\title{
Updating the Abstract-Concrete Distinction in Ancient Near Eastern Numbers
}

\author{
Karenleigh A. Overmann* \\ Center for Cognitive Archaeology, \\ University of Colorado, Colorado Springs
}

\begin{abstract}
The characterization of early token-based accounting using a concrete concept of number, later numerical notations an abstract one, has become well entrenched in the literature. After reviewing its history and assumptions, this article challenges the abstract-concrete distinction, presenting an alternative view of change in Ancient Near Eastern number concepts, wherein numbers are abstract from their inception and materially bound when most elaborated. The alternative draws on the chronological sequence of material counting technologies used in the Ancient Near East-fingers, tallies, tokens, and numerical notations - as reconstructed through archaeological and textual evidence and as interpreted through Material Engagement Theory, an extended-mind framework in which materiality plays an active role (Malafouris, 2013).
\end{abstract}

\section{Introduction}

Early token-based accounting has long been understood as involving a "concrete" concept of number, with the invention of writing enabling the development of an "abstract" or "second-order" number concept (e.g., Damerow, 1996a). This distinction between "abstract" and "concrete" numbers is thought to have been facilitated by the invention of writing, which enabled the separate representation of quantity (by means of numerical signs) from commodity (by means of graphic labels), information that had previously been conjoined in the shapes, sizes, and quantities of clay tokens (Schmandt-Besserat, 1992a). In this familiar account, an abstract concept of number was presumably something the Mesopotamians not only lacked but were incapable of achieving before writing was invented. As expressed in the literature, "tokens reflected an archaic mode of 'concrete' counting prior to the invention of abstract numbers. This is supported by the fact that there are no tokens to express abstractly numbers such as ' 1 ' or ' 10 '. Instead, a particular counter was needed to account for each type of goods: Jars of oil were counted with ovoids, small measures of grain with cones, and large measures of grain with spheres” (Schmandt-Besserat, 1992a, p. 6). Similarly, "[p]rior to the invention of the sexagesimal place value system [in the late $3^{\text {rd }}$ millennium], there was no concept of abstract numeration: numbers were thought of not as independent entities but as attributes of concrete objects - the length of a line, for instance, or the quantity of sheep in a flock” (Robson, 2007, p. 75).

The abstract-concrete distinction has become fairly entrenched in the literature on Ancient Near Eastern numbers and thinking: "[T]he litany is often repeated that the Mesopotamians were incapable of abstract thought, that their languages lacked terms to express concepts" like numbers (Glassner, 2000, p. 55). It is particularly associated with the extensive research and publication on

\footnotetext{
${ }^{1}$ Correspondence concerning this article should be addressed to the author at karenleigh.overmann@keble.oxon.org.
} 
Neolithic tokens by Archaeologist Denise Schmandt-Besserat (e.g., 1977, 1978, 1982, 1986, 1992a, 1992b, 2010, 2016), as well as the cognitive analyses by developmental psychologist Peter Damerow (1988, 1996a, 1996b, 2007, 2010, 2012), who explicitly rooted the concrete-to-abstract notion in the work of psychologist Jean Piaget. Drawing in particular on work by sociologist Lucien Lévy-Bruhl (e.g., 1910, 1927), Piaget applied his ideas on cognitive development in children (e.g., how the thinking of children differs from that of adults; how the latter progressively develops from the former) to entire societies. These he divided into two groups. In the first were traditional and archaic societies, whose "prélogique" he compared to the "mentalité enfantine"; the second included his own and similar Western societies, labeled rational for their purported logical, adult thinking (Piaget, 1928, pp. 191-194). Such characterizations, pervasive in $19^{\text {th }}$ century discourse on cross-cultural differences in general and number systems in particular (e.g., Conant, 1896), have been considered untenable since the mid- $20^{\text {th }}$ century, not merely for their perjoration but also for the overt biases that subvert their conclusions.

If its basis is now terminologically and methodologically inapt, the idea that Ancient Near Eastern numbers were concrete before becoming abstract nonetheless labels real phenomena of change in the way numbers would have been conceptualized between the Neolithic (8300 to 4500 BC) and the Old Babylonian period (1900 to 1600 BC). One of the most significant changes was the separation of the representation of number from that of commodity in the late $4^{\text {th }}$ millennium (Schmandt-Besserat, 1992a; also see Friberg, 1994; Malafouris, 2010; Mattessich, 1994), which enabled the further elaboration of notations and pictographs into a complex mathematics and literate writing. By the $2^{\text {nd }}$ millennium, the Old Babylonian mathematicians had developed a socalled pure mathematics involving complex algorithms for calculating answers to artificial as well as practical problems (Friberg, 2007; Høyrup, 2002a, 2002b; Robson, 2007, 2008). However, they do not appear to have speculated much about the nature of number as a concept, an inquiry that would be taken up by the Greek philosophers in the $1^{\text {st }}$ millennium (Damerow 1996a, 1996b; Høyrup, 1994; Klein, 1968).

While its pervasiveness in the literature and association with unambiguous conceptual change make the abstract-concrete distinction difficult to challenge, the need to update it is both apparent and overdue for several reasons. First, as mentioned, applying Piaget's theory of cognitive ontogenesis to the development of societal thinking has fallen out of fashion, a reason in and of itself to reexamine its application to change in the conceptualization of Ancient Near East numbers. Second, the distinction has generated a number of related assumptions (e.g., that tokens were the first technology used for counting; that tokens were used in one-to-one correspondence with the things they counted, and without number-words) that can and should be reexamined once their Piagetian underpinning has been removed, especially in light of evidence suggesting precursor technologies and the complexity of structure reflected by the tokens themselves. Finally and perhaps most importantly, the abstract-concrete distinction may underestimate the role of materiality in structuring and changing how numbers are conceptualized. This misses the opportunity provided by the Ancient Near Eastern sequence of counting devices, which spanned the realization of initial number concepts to their elaboration into one of the ancient world's great mathematical traditions, ultimately contributing to the modern conceptualization of number. Analysis of the sequence may shed new light on the changes characterized by the abstract-concrete distinction and perhaps the way materiality functions in human cognition more broadly.

The challenge, then, is to update the abstract-concrete distinction in a way that both respects historical scholarship and provides new insight into the phenomena it characterized. After 
reviewing the history of the abstract-concrete distinction, an alternative view of change in Ancient Near Eastern numbers will be presented, one that encompasses materiality as a constitutive part of the cognitive system for numbers, and in which numbers are abstract from their inception and materially bound at their most elaborated. This alternative view of how numerical thinking is structured and changes over time draws on the sequence of material counting technologies used in the Ancient Near East, as reconstructed through archaeological and textual evidence (Overmann, 2016a) and as interpreted through Material Engagement Theory, an extended-mind framework in which materiality plays an active role as a component of cognition with the ability to influence behavioral and psychological change (agency) and acquire and instantiate meaning (semiotic function) (Malafouris, 2013). The alternative corresponds well to Damerow’s (1988) insight that the conceptualization of numbers was informed by their material representations, as well as his concern that developmental psychology, especially as it had been applied to historical-cultural development by Piaget, might not be ideal for understanding change in the conceptualization of number (also see discussion in Nicolopoulou, 1997).

\section{The Piagetian Roots of the Abstract-Concrete Distinction}

Piaget was a clinical psychologist best known for his work on cognitive development in children. In his theory of how adult cognition develops from childish thinking, Piaget asserted that children of any and all cultures pass through four ontogenetic stages: a sensorimotor stage (0-2 years) characterized by experiencing the world through sensation and movement; a preoperational stage (2-7 years) characterized by the lack of concrete logic or the ability to manipulate information mentally; a concrete operational stage (7-12 years) characterized by logical thinking limited to matters that involved physical manipulation; and a formal operational stage (12+ years) characterized by abstract thought, metacognition, and complex problem solving (Inhelder \& Piaget, 1958; Piaget, 1937, 1952). (Follow-on elaboration and enhancement of Piaget's work on cognitive ontogenesis, known as Neo-Piagetian theories, have added higher-order stages and substages, not explicated here as tangential to the present argument.) Piaget held that the ontogenetic stages were necessarily progressive because the prior ones needed to be in place before any subsequent ones could develop. While scholars in the last half century have stopped applying Piaget's theory to how societies think, his work on cognitive ontogenesis has remained influential in fields like developmental psychology and approaches like constructivism.

For Piaget, societies possessed distinct mentalities, as did children and adults, which he called primitive for traditional or archaic societies and rational, scientific, or civilized for modern, industrialized ones. He asserted the so-called primitive mentality of the "civilisations inférieures" resembled the "mentalité enfantine” (Piaget, 1928, pp. 200-201) in several respects:

On peut citer comme exemples la tendance à l'affirmation sans preuve, le caractère affectif de la pensée, son caractère global, non analytique (le syncrétisme), l'absence de cohérence logique (des principes de contradiction et d'identité considérés comme des structures formelles), la difficulté à manier le raisonnement déductif et la fréquence des raisonnements par identification immédiate (participation), la causalité mystique, l'indifférenciation du psychique et du physique, la confusion du signe et de la cause, du signe et de la chose signifiée, etc. Nous ne prétendons nullement, cela va sans dire, que chacun de ces traits se présente de la même manière chez le primitif et l'enfant, et il faudrait un volume pour marquer les nuances, pour souligner l'aspect fonctionnel des ressemblances 
et écarter les identifications brutales. Mais, dans les grandes lignes, nous pensons qu'il y a des analogies. (Piaget, 1928, p. 194)

Piaget also identified separate mechanisms for each, with "tradition sociale" constraining the primitive mentality and "l'égocentrisme de la pensée" that of the child, and these constituted "l’obstacle principal à la mise en parallèle du primitif et de l’enfant” (Piaget, 1928, p. 192).

Piaget was addressing the important question of how societies derived truth from opinion, the development of societal thinking that involves, as ontogeny does, the acquisition of concepts and the construction of structures of thought. He was not wrong about there being similarities between the two processes: Both involve interactivity with social others and the physical world, both are progressive in the sense that later constructions depend on previous ones, and both produce cognitive outcomes that are relatively consistent when viewed across individuals and societies. Some similarity is to be expected, given that any society is composed of individuals enculturated from birth to reproduce and transmit its behaviors, knowledge, and manner of thinking. However, while Piaget differentiated mechanisms of social constraint and egocentrism, he does not appear to have made a similar distinction between the child's acquisition of existing social knowledge, which entails the preexistence of concepts, terminology, and knowledgeable others, from its social invention, where new knowledge is generated and adult activity dominates discovery, transmission, and conventionalization (indeed, since the developmental acquisition of number involves ontogenetic maturation, children are unlikely to be a significant factor in numerical elaboration, though the requirement to explain things in terms they can understand may plausibly relate, at least in some small part, to numerical explication). The processes overlap, as invention involves knowledge and skills acquired when young that are perhaps ontogenetically organized in ways that facilitate creativity (e.g., analogous to the way children turn pidgin into creole), and both adults and children participate in the transmission and conventionalization of new knowledge. ${ }^{1}$

The similarities and overlaps between the child's acquisition of existing knowledge and a society's generation of new knowledge may have further relevance to the history of thought (Oesterdiekhoff, 2016). Here it suffices to acknowledge that Ancient Near Eastern children would have acquired knowledge of, behaviors associated with, and ways of thinking about numbers both informally (e.g., via their exposure to numbers as lexical and grammatical features of language; through their everyday use of numbers) and formally (as part of scribal training) and that this was likely to have informed the social elaboration of numerical concepts, even as increasing elaboration may have pushed acquisition toward greater formality. However, the present focus is not the child's acquisition of number concepts but how the concepts themselves changed over time as a body of social knowledge, Damerow's concern.

\section{Damerow's Application of Piagetian Theory to Ancient Near Eastern Numbers}

In researching ancient mathematics, Damerow deserves credit for advancing the understanding of early Mesopotamian numerical systems through his methodical analysis of the extant data. This helped elevate the topic from the dismissive treatment it more commonly received from mathematical hands, where Babylonian and Egyptian contributions have often been

\footnotetext{
${ }^{1}$ Piaget envisioned the child's acquisition of number as a process of developing "biologically predetermined" cognitive structures through environmental interaction; Damerow argued that environmental interaction (particularly with material representations of number) could influence the substance of numerical content (Damerow, 1998, p. 128). With Material Engagement Theory, material structures become a constitutive component of numerical cognition.
} 
considered rudimentary and "almost insignificant" in comparison to those of the later Greeks: These mathematical traditions were the merest "scrawling of children just learning how to write as opposed to great literature," castigated as much for their practical application and empirical and inductive methodology as for making "hardly any progress [over a period of 4000 years]" and "[lacking] the spirit of mathematics" (Kline, 1967, p. 14). In contrast, the excitement with which Damerow (and indeed, predecessors, contemporaries, and successors that include Thureau-Dangin [1921], Neugebauer [1957], Vogel [1959], Vaiman [1961], Marvin Powell Jr., Jöran Friberg, Jens Høyrup, Hans Nissen, and Robert Englund, Eleanor Robson, Christine Proust, and Grégory Chambon) investigated the methods, context, and results of the Ancient Near Eastern mathematical tradition was a significant force in motivating scholarly interest from the historical and psychological perspectives.

Damerow analyzed numerical changes from the Paleolithic to the modern age, targeting those that occurred in the Ancient Near East between the Neolithic, which encompassed the invention of agriculture, significant increases in population, and the intensification of sedentism, specialization, stratification, and interconnectedness, and the Bronze Age, which oversaw the development of a complex mathematics and literary tradition. Distinctive technologies are associated with each: clay tokens with the Neolithic, numerical notations the Bronze Age. These were intermediated by forms that resembled tokens - numerical impressions and archaic numerical notations - whose resemblance attests to the numerical meaning of the tokens (at least the plain ones used in $4^{\text {th }}$-millennium accounting - spheres, cones, disks, cylinders, and tetrahedra; Friberg, 1994), and whose use (and the subsequent development of pictographic labels for the commodities they enumerated) are widely credited as constituting the invention of writing. In characterizing numerical change using Piaget's theory of societal mentalities, Damerow associated the numerical notations with an abstract concept of number. This necessitated that the earlier technologies and the societies that used them, like Piagetian traditional societies, were concrete and associated with difficulty distinguishing sign (e.g., tokens) from signified (the objects they counted). Damerow wrote that the Neolithic bore "the closest resemblance with what we know from extant indigenous cultures at a stone age level. If, therefore, Piaget's assumption is correct that cognition in such cultures does not exceed the preoperative level, then the Neolithic Revolution in spite of the material progress did not fundamentally change the level of cognition achieved at the end of the Paleolithic Period” (Damerow, 1996b, p. 18).

Damerow advocated a four-stage model of Ancient Near Eastern numeracy, with the two highest stages each divided into two sub-stages (1996a, pp. 139-148; also see Table 1): Stage 0 was pre-arithmetical quantification "defined by the absence of any arithmetical activities"; Stage 1 was proto-arithmetical quantification that began "with the construction of one-to-one correspondences." Stage 2 consisted of symbol-based arithmetic "based on the manipulation of symbols according to rules derived from the construction of second-order representations of quantities and actions," with second-order representations indicating "thoughts about thoughts"; Stage 2A involved context-dependent symbol systems with "no general system of abstract number notations," while Stage 2B involved abstract symbol systems "no longer dependent on any specific contexts of application." Finally, Stage 3 consisted of concept-based arithmetic "defined by the construction of second-order representations of symbolic arithmetical transformations by means of mental reflection"; Stage 3A involved natural-language derivations "composed of statements and arguments encoded in natural language" with "explicitly defined" concepts of number, of which the "best-known early instances" came from ancient Greek mathematics, while Stage 3B involved symbolic derivations in which "the encoding of concepts in natural language [was] 
replaced by encoding in abstract symbol systems ... [with concepts] subsumed under generalized, unifying concepts," a progression "not completed before the end of the nineteenth century" AD.

Table 1: Damerow's Model of Conceptual Development in Ancient Near Eastern Numbers

\begin{tabular}{|c|c|c|c|c|}
\hline \multicolumn{3}{|r|}{ Stage } & \multirow{2}{*}{$\begin{array}{c}\text { Timeline } \\
\text { Before } 10,000 \mathrm{BC}\end{array}$} & Characterization \\
\hline 0 & & $\begin{array}{l}\text {-arithmetical } \\
\text { ntification }\end{array}$ & & No arithmetical activities \\
\hline 1 & Pro & $\begin{array}{l}\text { to-arithmetical } \\
\text { ntification }\end{array}$ & $\begin{array}{l}\text { Roughly } 10,000 \\
\text { BC }\end{array}$ & One-to-one correspondence \\
\hline \multirow[t]{3}{*}{2} & $\begin{array}{ll}\text { Syl } \\
\text { arit }\end{array}$ & $\begin{array}{l}\text { nbol-based } \\
\text { hmetic }\end{array}$ & & $\begin{array}{l}\text { Symbolic manipulation; second-order } \\
\text { representations of quantities and actions }\end{array}$ \\
\hline & A & $\begin{array}{l}\text { Context- } \\
\text { dependent } \\
\text { symbols }\end{array}$ & $\begin{array}{l}\text { Archaic numerals } \\
\text { (late } 4^{\text {th }} \text { mil. BC) }\end{array}$ & $\begin{array}{l}\text { No general system of abstract number } \\
\text { notations }\end{array}$ \\
\hline & B & $\begin{array}{l}\text { Context- } \\
\text { independent } \\
\text { symbols }\end{array}$ & $\begin{array}{l}\text { Cuneiform } \\
\text { numerals ( } 3^{\text {rd }} \text { mil. } \\
\text { BC) }\end{array}$ & $\begin{array}{l}\text { Independence from any specific contexts of } \\
\text { application (abstraction = abstract symbols) }\end{array}$ \\
\hline \multirow[t]{3}{*}{3} & & $\begin{array}{l}\text { hcept-based } \\
\text { hmetic }\end{array}$ & & $\begin{array}{l}\text { Second-order representations of symbolic } \\
\text { arithmetical transformations by means of } \\
\text { mental reflection }\end{array}$ \\
\hline & A & $\begin{array}{l}\text { Natural-language } \\
\text { derivations }\end{array}$ & $\begin{array}{l}\text { Greek } \\
\text { mathematics }\left(1^{\text {st }}\right. \\
\text { mil. BC) }\end{array}$ & $\begin{array}{l}\text { Natural language encoding of statements and } \\
\text { arguments; explicitly defined concepts of } \\
\text { numbers }\end{array}$ \\
\hline & B & $\begin{array}{l}\text { Symbolic } \\
\text { derivations }\end{array}$ & $\begin{array}{l}\text { Late } 19^{\text {th }} \text { century } \\
\text { AD }\end{array}$ & $\begin{array}{l}\text { Symbolic encoding of statements and } \\
\text { arguments; generalized, unifying concepts }\end{array}$ \\
\hline
\end{tabular}

Note: Compiled from Damerow, 1996a, pp. 139-148.

It is possible to agree with Damerow regarding the overall progression and relative chronology of his model, since numerical elaboration in later stages depends on numerical concepts in some form or another being available in earlier ones. Some of the model's timeline and characterizations are undoubtedly correct, as the representational separation of number and commodity was an abstraction that potentialized their further elaboration; Greek philosophers were indeed concerned, as Old Babylonian mathematicians appear not to have been, with the ontological status of number (Høyrup, 1994; Klein, 1968); and the emergence of generalized, unifying mathematical concepts relatively recently is historical fact (Gowers, 2008). Nonetheless, this partial acceptance does not preclude rejecting the ideas that tokens were confused with the objects they enumerated or that they represented concrete numbers while written notations meant abstract ones. Further, the mechanism of change in societal thinking may not have been ontogenetic maturity but, as argued here, material engagement: Numerical content and structure were influenced by the material forms used for counting, associated behaviors, and psychological processing related to the acquisition of an elaborated cultural system. That is, conceptual change, and perhaps change in psychological processing as well, would have occurred through change in the materials used to represent and manipulate numbers. Material engagement also provides a mechanism for conceptual structuring and change at the level of both individual and society without needing to appeal to ontogenesis for either. 
Damerow's model also inherited some of the shortfalls of Piagetian theory: For example, Piaget's research in ontogenetic development and numerical acquisition focused on children enculturated into numerate Western societies, generating findings whose cross-cultural generalizability has been convincingly challenged (e.g., Dasen, 1994). To what degree the cultural elaboration of numbers influences their acquisition remains an open question, given that the perceptual ability to appreciate quantity, which governs how quantity is experienced and to some extent influences how numbers are cognized, appears stable across significant differences in numerical elaboration (Henrich, Heine, \& Norenzayan, 2010). Generalizability of Piaget's theory of societal mentalities faces similar difficulties: If indeed generalizable, Piagetian stages similar to those Damerow construed for Mesopotamian numbers should be found in Egypt, China, and Mesoamerica, the other ancient mathematical traditions, but they are not (Chrisomalis, 2005). Moreover, the emergence of context-independent numerical representations from multiple systems of context-dependent ones marked for Damerow the critical transition to abstract numbers in the Ancient Near East. Fitting this into Piagetian theory meant excluding the possibility that the Neolithic cultural elaboration influenced how numbers were conceptualized, despite the likelihood that numbers both enabled and were themselves elaborated during the Neolithic Revolution, as there is a well-established (if poorly explained) cross-cultural correlation between numerical elaboration and the complexity of material culture generally (Epps, Bowerin, Hansen, Hill, \& Zentz, 2012).

\section{Abstract and Related Assumptions}

The distribution of numerical meaning across multiple number systems in the early numerical signs (i.e., the tokens, numerical impressions, and archaic notations) made their value context-dependent and also specified the commodity they counted. Damerow assumed this necessarily marked the absence of an abstract concept of number. As this meant there were no abstract number concepts needing linguistic expression, it was also assumed that the early numerical signs coexisted with a restricted numerical lexicon (i.e., one in which it was possible to count no higher than 20 and perhaps no higher than 3 or 4; Comrie, 2013). Finally, tokens are often discussed as if they were the first counting technology and were used in one-to-one correspondence with the objects they counted. These assumptions are closely related to one another and to the various ways the term abstract has been used in the literature, which will be examined first: Abstract can refer to a concept formed or changed through the cognitive process of abstraction. The term can also have the sense of something intangible; that no longer faithfully resembles what it intends to depict; that has become distilled, truer, or rarified; that is theoretical rather than practical when applied; or a number that is unspecified in not referring to any particular object. After these are examined, an additional way of understanding abstract as the distribution of a concept over multiple material forms, and hence, its seeming independence from any particular form, will be offered.

As a cognitive ability, abstraction is a process of concept formation and change that encompasses generalization (identifying properties common to sets of objects; inducting from particulars; applying inductive insights to new domains), decontextualization (extracting content from its original circumstances to remove their influence on its meaning), synthesis (combining parts into wholes, often in such a way that sums are greater than the parts), and reification (reinterpreting processes or relations as permanent entities in their own right, making them available to act as inputs to other processes or relations) (Dreyfus, 1991; Ferrari, 2003; Sfard \& Linchevski, 1994). As a process, abstraction is as much behavioral and material as it is mental. For 
example, numbers begin as a recognition that sets of objects share quantity (Russell, 1920), generalization occasioned by behaviors like one-to-one correspondence that manipulate sets of objects into arrangements whereby their shared quantity can be appreciated. Change in the venue for counting-performing it in a place different from the one where the enumerated goods are located-would decontextualize counters from counted. And blank space in the sexagesimal place value system developed in Mesopotamia toward the end of the $3^{\text {rd }}$ millennium would be reified, first as a meta-sign for the absence of any number, and ultimately as a number in its own right, zero (Rotman, 1987).

Schmandt-Besserat labeled objects thought to be numerical counters "tokens," a term that invoked the type-token distinction of philosopher Charles Saunders Peirce. A Token is "a Single object or thing which is in some single place at any one instant of time, such ... thing being significant only as occurring just when and where it does"; in comparison, a Type "is not a Single thing or Single event. It does not exist; it only determines things that do exist” (Peirce, 1906, p. 506). Where a Peircean Token is tangible, a Type is not, making the former presumably concrete, the latter abstract. Abstract products need not inhabit the same phenomenological level, as a (physical) drawing of a triangle differs from the (ideal) geometrical concept of one. That is, the concepts realized by abstraction are "not concrete and tangible” (Gowers, 2002, p. 16), a characterization often applied to mathematical objects. Formally, abstract objects are conceived as non-mental and nonsensible (e.g., Plato's ideal forms) or as lacking spatiotemporal locus, causal efficacy, or both (Linnebo, 2013; Rosen, 2014). This is mathematical realism, the view that mathematical objects have an existence independent of the mind and sensible world. From a different perspective, being intangible or otherwise imperceptible is true of mental content, to anyone other than the person whose mental content it happens to be, unless it is made public some fashion (e.g., materially, linguistically, emotionally, etc.). Intangibility is implicit in intuitionism, the idea that numbers are intuited and mathematical objects mentally constructed (Brouwer, 1981). The debate about whether numbers are mind-external or -internal need not be settled to recognize that either way, numbers would be intangibly abstract from their inception as comparisons of quantity between two sets of objects; their intangibility means that numbers depend on material instantiation for their expression, explication, manipulation, and visualization (Fig. 1). More interesting is the fact that they can be materially realized and systemically manipulated in the first place, as not every intangibly abstract concept or group of related concepts can as easily be (e.g., justice; societal norms). However, while conceptual content is related to the materiality that gives it form, there is arguably more to the former than the latter instantiates (were this not so, archaeological interpretation would be a much simpler matter). If the instantiating material makes the concept comprensible (Frege, 1953), what its substance is (and is not) capable of has potential influence on the resultant content.

A representation whose form has become relatively independent of the object it once depicted is abstract in the sense Schmandt-Besserat initially used: "Hypotheses about the origin of writing generally postulate an evolution from the concrete to the abstract: an initial pictographic stage that in the course of time and perhaps because of the carelessness of scribes becomes increasingly schematic” (1978, p. 50). Over several centuries, the pictographs used as archaic commodity labels did become less recognizable as the objects they depicted (Fig. 2), but probably not through inattention or neglect. Rather, decreased iconicity was an effect of emerging literacy: The neural reorganizations involved in recognizing handwritten written objects by their features relaxed the need to preserve the original iconic form; other contributing factors included motor habituation, biomechanical effectiveness, and visual discriminability (Overmann, 2016b). Decreased 
iconicity also affects numerical signs (e.g., as the sign 2 was once two strokes), but to a lesser extent than non-numerical ones because of how they represent meaning and are organized systemically. Numerical signs can instantiate their meaning (Malafouris, 2013), as two strokes or wedges are two. Even in abstract (e.g., 2) or symbolic form (as a small sphere meant an amount of $\mathrm{N}_{01}$ and a wedge meant 10), numerical signs are semantically meaningful without phonetic specification, a quality Powell (1971) noted Sumerian numbers share with modern Western numerals. This is because numerical signs share relations with each other and are organized in a limited number of basic patterns (only five in the classification schema of Chrisomalis, 2010), making them recognizable as numbers even in unknown languages and scripts. By comparison, non-numerical signs symbolize their meaning, making them relatively ambiguous regarding their intended semantic and phonetic values (e.g., as the pictograph of a head could mean head, person, or capital). Further, the organization of non-numerical language is much more variable, and context affects both semantic and phonetic value. These factors pressure non-numerical signs to incorporate semantic and phonetic clues that alter their appearance. Thus, while both numerical and non-numerical signs lose iconicity through factors involved in emergent literacy, non-numerical signs lose more (i.e., become more abstract in this sense of the term) than numerical signs do.

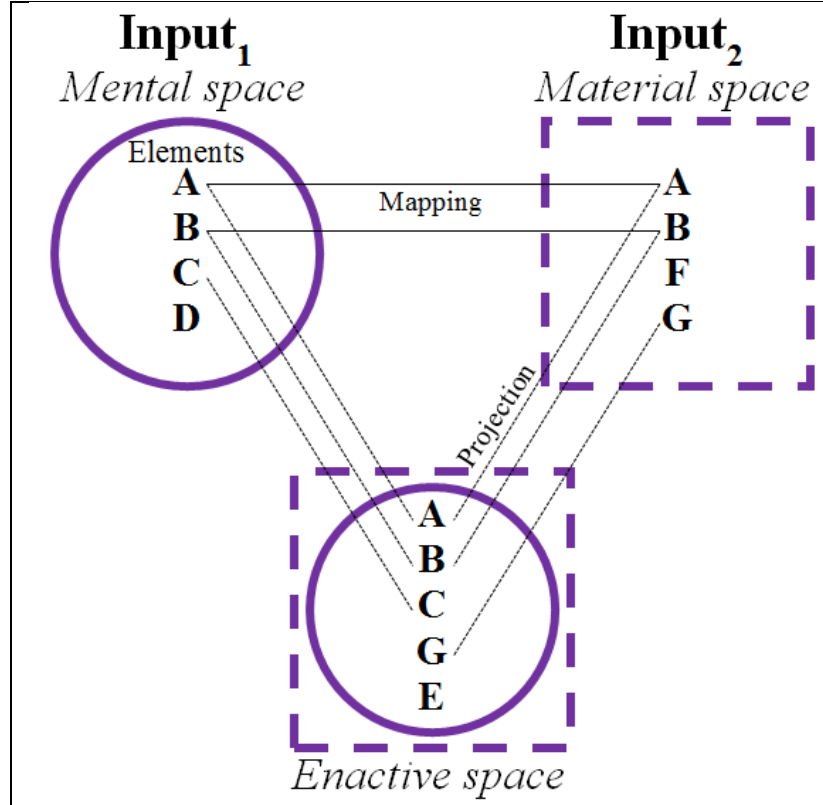

Blend
Fig. 1: Model of a conceptual blend anchored and stabilized by a material form (adapted from Malafouris, 2013, Fig. 5.2). Blending "operates on ... Input mental [and physical] spaces to yield a third space, the blend. The blend inherits partial structure from the input spaces and has emergent structure of its own" through processes like contextualization, recognition of inter-element relations, and elaboration (Fauconnier, 1997, pp. 149-151, emphasis original). The letters represent elements such as knowledge (mental), features (physical), and capacities (both). The lines between elements are "ontological correspondences [between internal (mental) and external (physical) domains that] primarily involve connections of identity, analogy, similarity, causality, change, time, intentionality, space, role, and part-whole, and in some cases also of representation" (Malafouris, 2013, p. 100). Projection is

triggered and supported by an "external manipulable structure" that interacts with and influences mental capabilities and conceptual content; it augments and contextualizes the observed material form with knowledge, attended features, construed relations, etc., thereby going "beyond what is immediately perceived" (Malafouris, 2013, p. 102) to become "transformational and not merely informational" (di Paolo, Rohde, \& de Jaegher, 2010, p. 39). Blending enables numerical intuitions to be made tangible, expressed, explicated, manipulated, and visualized.

Abstract can also connote something that has become distilled, refined, or purified to its essential nature, perhaps in the process becoming more accurate and true, or something that has achieved a state more rarified and complex than what preceded it, making it more difficult for the 
uninitiated to comprehend. Certainly, numbers have changed over the past millennia, and if distilled and truer, they have also become more complicated and difficult to grasp in their totality: Old Babylonian numbers are relatively simple compared to their Greek counterparts, whose foundational ontological role connected the sensible and nonsensible realms, not just for themselves but for all things (Klein, 1968); with their modern counterparts, it is not only possible but desirable to prove something as seemingly self-evident and incontrovertible as $1+1=2$ (Peano, 1889; Whitehead \& Russell, 1927). Materiality has been central to this evolutionary development: It collects and consolidates social knowledge and interfaces what a society knows and an individual learns, distributing elaborational effort over space and time (Haas, 1996; Hutchins, 1995). As the conceptualization of number differs by evolutionary locus, a further distinction can be made between a material form and the concept it represents, not merely because the former makes the latter tangible: At least part of conceptual content relates to the number system, as the relations among numbers are as critical to what numbers are and what they can do as are notes to music and sounds to language (Plato, 1892). As numerals (and other material forms) make numbers accessible, their "perceived relationships ... are taken as proxies (consciously or unconsciously) for relationships among conceptual elements” (Hutchins, 2005, p. 1562). Material representation makes numerical relations accessible in a way that enhances the visualization of patterns and bypasses psychological constraints (e.g., working memory capacity); the evolutionary mechanism this provides is one in which material properties are as pertinent as mental ones.

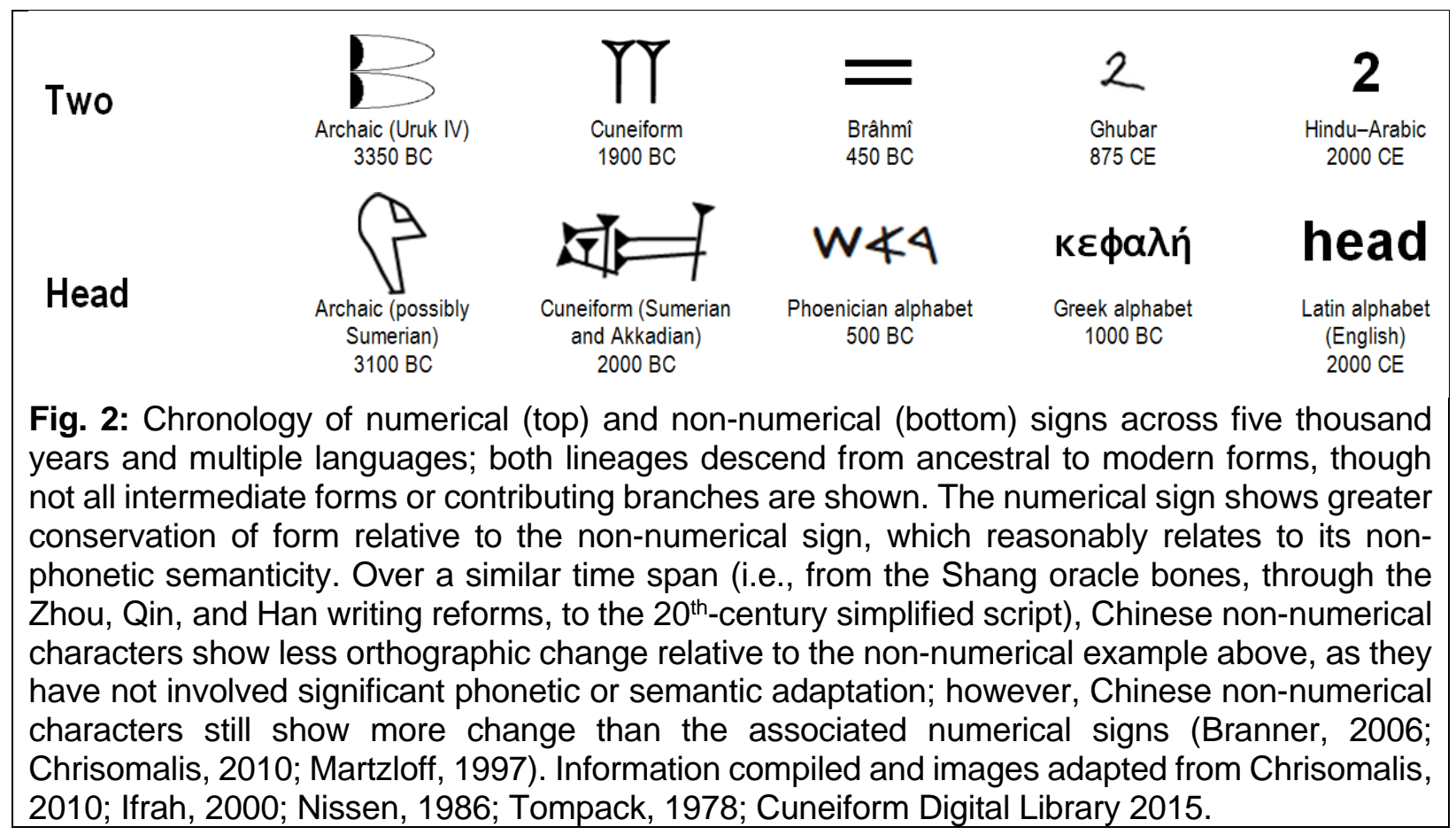

As numerical relations become more explicit (e.g., not just "greater than" and "plus one" but " 11 is 3 more than 8 "), they also become more accessible to manipulation. This relates to the sense in which abstract, theoretical, or pure mathematics contrasts with its mundane counterpart, the everyday use of numbers: The former is concerned with numerical relations, the latter with 
questions of how many and how much, the difference between searching for higher prime numbers and summing a grocery bill. A pure mathematics is said to have developed by the Old Babylonian period (Friberg, 2007; Høyrup, 2002a, 2002b; Robson, 2007, 2008), as discerned through complex calculations with quantities or measurements that could not exist in actuality, making them pure "in substance," though they remained "applied in form" in dealing with matters like military construction and agricultural yield (Høyrup, 1994, p. 8; emphasis in original). Greek mathematicians, in comparison, investigated knowledge "systematically and for its own sake (or at least without any intentions of application)" (Høyrup, 1994, p. 25; emphasis in original), a distinction Damerow noted in his model. However, Greek concern with conceptual content, definitions, and ontological status was informed by the abstract mathematics developed in Mesopotamia, and it was not limited to numbers or mathematics but rather involved the entire spectrum of scientific thought as it was then known. Thus, while representational separation undoubtedly facilitated the complex and artificial calculations of Mesopotamian mathematicians and contributed to the later conceptual work of the Greeks, the further elaboration of number concept by the latter cannot be ascribed solely to independent mathematical developments but must be contextualized as part of continued change in mathematical thinking and broader change in scientific thought.

The terms concrete and abstract have another connotation, familiar in discussions of Ancient Near Eastern numbers: specified or unspecified, or connected (or not) to the objects of which a number is the quantity (e.g., Schmandt-Besserat, 1981). To Damerow, the early numerical signs were specified, as they referred to particular commodities, and cuneiform numbers were unspecified, as they did not so refer. However, even the later Greeks lacked unspecified numbers. The everyday numbers used in counting and calculating (arithmos) were so thoroughly identified with the sensible objects they quantified that while a number designating different objects had the same quantity, it differed with respect to the objects it designated: The ten used with horses thus differed from the ten used with dogs (Klein, 1968, drawing on Aristotle). Plato's pure or nonsensible numbers were similarly specified: One was not a number but an indivisible unity, of which the pure numbers, two and higher, were multiples and thus specified (this construct created some difficulty, as the indivisibility of one meant that pure numbers could not be divided into fractions like arithmos could be) (Klein, 1968). Against Damerow's model, this suggests that Greek specified numbers were less abstract than cuneiform unspecified numbers, or that cuneiform numbers were not really unspecified (perhaps in referring to the metrological systems they intermediated; Robson, 2008), or that the Mesopotamians may have distinguished, as the Greeks did, the quantity of a number (shared) from its designation (specified). Certainly, Mesopotamian length and area calculations were specified, since continuous extents are ratios of some known measure, not discrete items subject to individuation and enumeration. The idea that number could be unspecified was the work of Renaissance mathematicians like Viète, Stevin, and Descartes, part of a larger reconceptualization that included one, zero, fractions, infinity, and unknown numbers in the same symbolic class as the positive integers and which unified continuous and discrete numeration (Klein, 1968; Rotman, 1987, 2000). The point is not to reassign abstract numbers to the Renaissance (or indeed, to the late $19^{\text {th }}$ century, where Crossley [1987] suggests numerical abstractness developed suddenly from a purported previous concreteness through work by Dedekind), but to draw attention to the fact that the Mesopotamian numbers represented by the early numerical signs, considered in total across the multiple systems they instantiated, referred to a much broader range of objects than what a tally might designate. This attribute might have been acknowledged as representing abstract numeration had the early numerical signs not been labeled as concrete. 
Beyond specifying particular things or nothing whatsoever (except perhaps each other), numbers can apply to anything and everything (it is left to the reader to determine whether this is best characterized as specified or not): "For number applies itself to men, angels, actions, thoughts, every thing that either doth exist or can be imagined" (Locke, 1690, Book 2, Chapter XVI, Sect. 1). The set of entities over which numbers can range becomes functionally limitless, a significant expansion compared to the relatively few commodities specified by early Mesopotamian numerical signs. This expansion, however, obscures a similar phenomenon in the material instantiation of number, where the incorporation of multiple material forms has three major effects: First, multiple instantiating forms enable comparisons of what they share and, more importantly, where and how they differ (e.g., as tokens were manipulable but numerical impressions were fixed). The contrast between forms (and language) potentializes elaboration, relative to systems with fewer forms (e.g., the Oksapmin body counting system prior to its exposure to Western mathematical practices; Saxe, 2012; reinforcement between the ordinal sequence provided by both the single material form and language yielded a stable system). In the Ancient Near East, not only were a variety of forms used, there were multiple numerical systems in contact with each other, whose different organization (e.g., Sumerian sexagesimal; Akkadian and Elamite decimal) would have provided contrasting elements. New material forms provide additional ways to represent and manipulate number concepts, the potential for novel structure, and material contrasts that may serve to highlight differences and foster insight.

The concept of number also incorporates attributes from the various material forms used to instantiate it: For example, numerical notations became manipulable once the relations between numbers had been sufficiently explicated and learned and suitable algorithms were formulated. But notations are fixed, not manipulable, which suggests they incorporated the manipulability of the earlier tokens, a development perhaps involving some awareness that what older forms enabled should be possible with newer forms. The concept of number also helps perpetuate these attributes across changes in material form: As their representation on the outsides of bullae indicates, tokens likely preserved the linear ordering by increasing magnitude of fingers and tallies, despite the potential for other organizational schemes (e.g., in a circle rather than a line; random or alternating magnitude; etc.) implied by their manipulability. Further, though once made they were fixed, the notational forms (i.e., the numerical impressions on bullae and envelopes, archaic numerical notations, and cuneiform numbers) were consistently ordered linearly and by increasing magnitude, though they too could have been otherwise organized during the process of manufacture. However, material forms and the concepts they instantiate condition those who use them to things working in certain ways. Familiarity and habituation narrow the range of behaviors possible with newer forms, enabling the structure of older forms to influence the structuring potential of newer forms.

Finally, when the concept of number is instantiated by a variety of forms, it becomes in a sense independent of any of them, yet another way of understanding the term "abstract." To paraphrase Miller (1980, p. 4) on the independence of the concept money from the many forms it can assume: Numerals are not numbers but a form of number; whatever its real nature, the concept of number is revealed through the form(s) that instantiate(s) it (Overmann, 2017). The use of multiple forms implies a concept that has become independent of any particular form, something that is true of the Western number concept: We count with our fingers, make tally marks, use coins (a material form similar to tokens in being manipulable and numerically interrelated), write numbers on paper and chalkboards, type them into calculators and computers, etc. The concept of number encompasses all of these various material forms (and more that have not been listed), along 
with aspects of only some of them (e.g., linearity; manipulability), characteristics that may not be implicit in every particular form but perpetuated through conceptual content. The potential persistence of tallies and tokens thousands of years after their first appearance in the archaeological records (e.g., Henkelman \& Folmer, 2016; MacGinnis, Monroe, Wicke, \& Matney, 2014), the presumed persistence of finger-counting to the point where it appears in the textual record, and indeed, the distribution of numerical value over multiple systems of early numerical signs (including the tokens), suggest that Mesopotamian numbers were similarly distributed across, and thus independent of, the different forms of materiality used to represent and manipulate them, and that this independence perhaps emerged in the Neolithic.

In sum, number is abstract in being formed and changed through the cognitive process of abstraction. It is abstract in its intangibility and subject to some abstractness in losing iconicity. It is abstract in the sense that its content changes over time through elaboration, in being applied theoretically, in expanding its range of potential application, and in becoming less dependent on particular material forms. Yet while number is abstract from its inception, it remains bound, however loosely, to the materiality that gives rise to it as concept, that makes it tangible and accessible and manipulable, that stabilizes and makes it generationally persistent, and whose properties inform its character while enabling it to change. Rather than being conceived as being "concrete" at some times and "abstract" at others, number should be acknowledged to have a dual abstract-concrete nature (with the quality "abstract” as stipulated and numerical content, structure, and organization changing as described). With number as a concept that emerges from the interaction of the psychological, behavioral, and material elements of numerical cognition, the "abstract-concrete" distinction collapses. ${ }^{2}$

\section{Related Assumptions}

Damerow's idea that the early numerical signs entailed concrete numbers was derived from their meaning, which was distributed, context-dependent, and specified: In the Neolithic, the numerical meaning of tokens varied geographically and temporally, creating an impression there was no abstract concept of number to unify them (this is compounded by a tendency to label any small clay object as a token; archaeological contexts being ambiguous regarding intended use; among other criticisms; see Englund, 1998; Friberg, 1994; Zimansky, 1993). By the late $4^{\text {th }}$ millennium, numerical signs also distributed their meaning between multiple, commodity-specific systems, in which conventions of shape, size, and order encoded both number and commodity and a particular sign could hold different values (i.e., polyvalency) relative to higher- and lower-value signs (Nissen, Damerow, \& Englund, 1993; also see Fig. 3). Value that was distributed, contextdependent, and specified suggested to Damerow a concrete concept of number. However, specification may have been an improvement over earlier, non-specifying technologies (more on this later). Further, distributed, context-dependent, specified numbers need not be concrete: the question how many? implicitly means how many [what]; 10 can mean ten or two; and both are associated with thoroughly abstract numbers. The idea that distributed, context-dependent specificity signaled concrete numbers is absurd, as it would make those familiar with them "less numerate than the average Sumerian who did not use texts, only number words" (Chrisomalis, 2005, p. 4). And as discussed, the distribution of numerical meaning over multiple representational

\footnotetext{
${ }^{2}$ This is not an argument for retaining the term "abstract," but rather, a stipulation that "independence" is another aspect of the quality to which "abstract" has historically been applied.
} 
systems may have signified an abstract concept of number, in the sense of being independent from any particular material form.

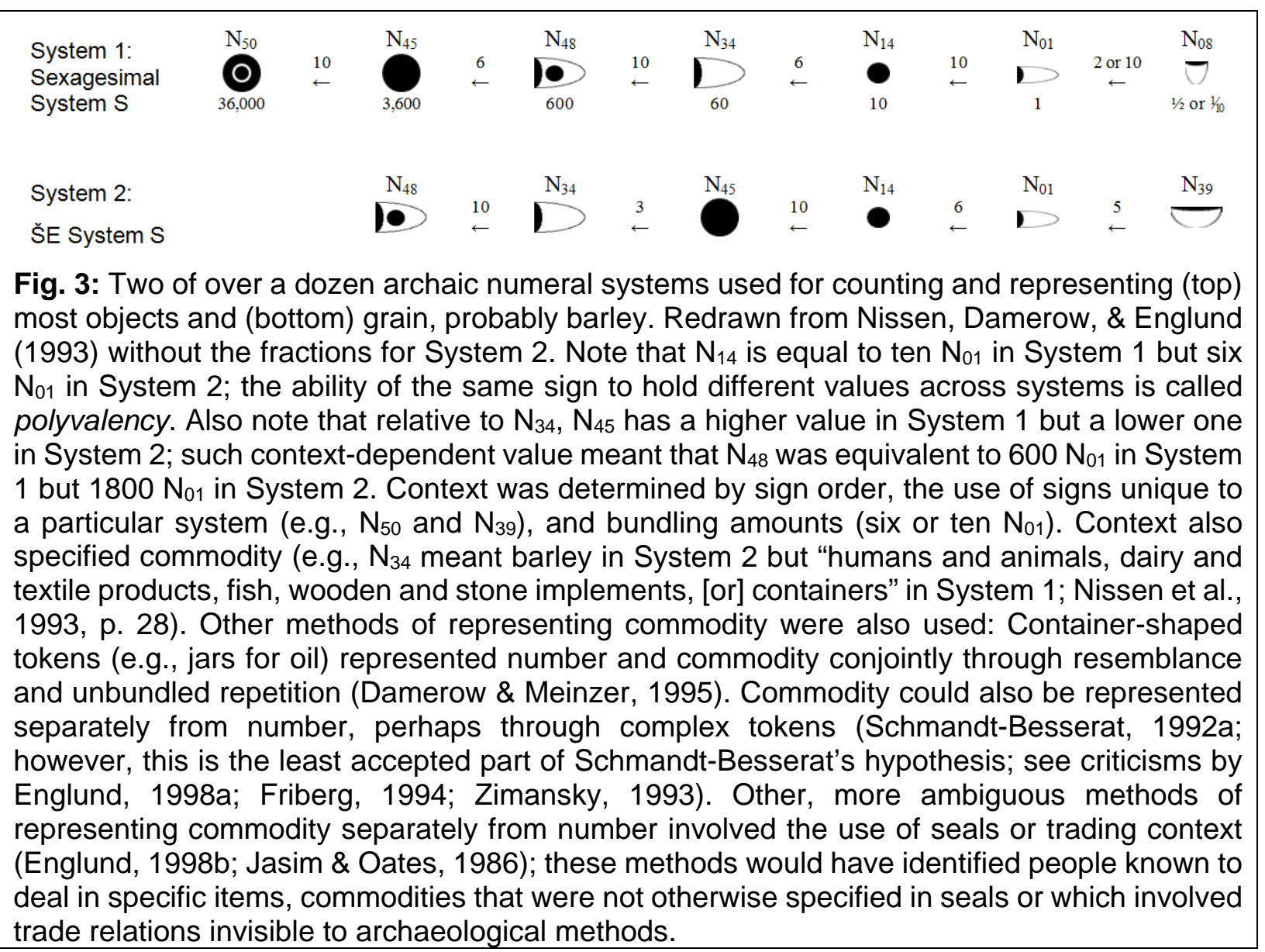

Rather than indicating a concrete number confusing sign with signified, conjoint representation may have simply been the Mesopotamian solution to a common problem, how to represent number and commodity in material form prior to the invention and availability of writing. In traditional societies, when a hunter marks his arm or the ground to count the days he has traveled or the enemies he has killed (Morgan, 1852; Pelleschi, 1896), he is unlikely to conflate the marks with either but simply represents the quantity of what he counts with the marks and maintains the knowledge of what he counts separately, perhaps in memory or the context of discussion. Granted, without their separation, further elaboration of the representation number and commodity is less likely. However, once the amount and duration of what needs to be remembered exceeds the capacity and persistence of human memory, some more capacious and durable method will be developed, and it may at some point involve representational separation. Other societies have solved the problem similarly to the way the Mesopotamians initially did, by means of encoding quantity, shape, and/or position; these devices include the Peruvian quipu, knotted string systems used in Peru, Bolivia, and Germany, Roman counting board, Chinese and Roman abacus, and Japanese Soroban (Zhang \& Norman, 1995). None of these has been labeled as representing a 
particularly concrete notion of number, despite the similarity of their conjoined representation with that of the early numerical signs, impressions, and tokens of the Ancient Near East.

The idea that early numerical signs (e.g., tokens, impressions, proto-cuneiform) were used with a restricted numerical lexicon relates to the idea that concrete thinking precluded both concepts of and words for abstract numbers (previously discussed) and to the inexpressiveness of early writing (i.e., the need for greater specificity in non-numerical signs). Sumerian numbers are typically described as a system in which early numerical signs were used with an oral counting sequence of only small quantities, signs for higher quantities like 600 were used without any corresponding vocabulary, and there was no ability to expand spoken numerals systematically before writing was invented (Høyrup, 2016). The textual evidence for a numerical lexicon thus requires context: The emergence of phonetic values for lexical and ordinal words (e.g. and respectively, one, thousand and first, thousandth) and grammatical singular-plural distinctions in the $3^{\text {rd }}$ millennium is more likely related to increased expressiveness (greater specificity) in writing, rather than indicating these features had only recently emerged in speech, for three reasons: The recency hypothesis (i.e., the idea that unrestricted lexical numbers emerged in Sumerian only after the invention of protocuneiform) and the fact that lexical forms precede grammatical ones (Corbett, 2000; Overmann, 2015) entail a significantly accelerated timeline at odds with the gradual pace of such grammaticalization generally (Heine, 2003; Traugott \& Heine, 1991). The recency hypothesis also ignores the import of token precursors and the semantic (non-phonetic) sufficiency of numerical representation, which suggest, respectively, the early development of a numerical lexicon and a late emergence for its phonetic representation. Finally, the recency hypothesis cannot account for the differences (e.g., marking method, distinctions expressed, animacy modulation) in Sumerian, Akkadian, and Elamite grammatical number that imply its separate development (i.e., before the significant inter-group contact of the late Neolithic).

A restricted lexicon also cannot be confirmed through the frequency of ordinal numbers (Dahl, 2015), as higher ordinal terms (e.g., sixth, tenth, hundredth) have a negligible frequency even in numerate languages with expressive scripts. Simply, the writing system's inability to express numbers phonetically does not entail there were no such words, especially given the semantic sufficiency of numerical representation mentioned previously. Further, while there is some lag between the initial representation of numbers materially (e.g., with fingers, gesture, tallies, etc.) and their linguistic expression, the lag is associated with relatively small, isolated societies, not populations the size and scale of the Ancient Near Eastern Neolithic. No known number systems have a lag the size of the one suspected for the Ancient Near East; rather, the ability to represent numbers in the hundreds materially invariably has a corresponding vocabulary, including an ability to express higher quantities in systematized and regularized ways (Comrie, 1989; Greenberg, 1978). Thus, early numerical signs for quantities in the hundreds are evidence of an unrestricted numerical lexicon, even if the associated phonetic values remained unknown until much later.

The assumption that tokens were the initial counting technology used in the Ancient Near East is countered on several grounds. First, there is archaeological evidence of possible tallies in the Upper Paleolithic Levant and known cultural diffusion between the populations that expanded into southern Mesopotamia from the Levant and Zagros Mountains during the Neolithic (Lazaridis et al., 2016; Reese, 2002). There is also textual and numerical evidence that implies fingercounting with a relative chronology that likely predates tallies and thus tokens as well. SchmandtBesserat (1992a) acknowledged both, but she did not address their significance as possible token precursors. Admittedly, both are ambiguous regarding counting. For the artifacts purported to be 
tallies, there is no definitive way to establish their use in counting, as marks on bones can be made for a variety of other purposes, including record-keeping, divination, music, fiber- or leatherworking, and tools of an unknown type (Reese, 2002). For fingers (and possibly toes as counting devices), the evidence takes two forms: One post-dates tokens as lexical terms (i.e., five-plus compounds for six through nine; ten- and twenty-cycles in higher lexical numbers) whose preservation had to wait for writing to be invented and then develop both the ability and the need to express the phonetic values of Sumerian number-words; the other consists of the productive cycles of 10 in the Sumerian, Akkadian, and Elamite number systems, ten-ness that typically derives from the use of the fingers in counting (Blažek, 1999; Edzard, 1980; Englund, 1998c, 2004; Friberg, 2007; Nissen, Damerow, \& Englund, 1993). ${ }^{3}$

However ambiguous the evidence of fingers and tallies might be, tokens were still unlikely to have been first, on grounds of their complex numerical representation: Tokens were related not just to what they counted but to each other as well, through bundling relations that made a single token of a higher value equal to 2-10 tokens of a lower value; in many (but not all) cases, bundling reflected metrological relations between containers used for the commodities in question (Nissen, Damerow, \& Englund, 1993). In adding a second dimension to their numerical representation (Fig. 4), bundling implies that the tokens were likely preceded by one or more one-dimensional technologies. (A possible counterargument, that tokens simply depicted what they counted, leaves the evidence of finger-counting and possible tallies unexplained.) Bundling also counters the idea that tokens represented one-to-one correspondence, since they were related to each other and not just the commodity they enumerated. In addition, bundling operations (i.e., the exchange of higherand lower-value tokens to simplify a compilation of tokens to its simplest and most accessible numerical form) necessitated a relative faculty with quantities like six and 10, which exceed the range of perceptual salience (i.e., the so-called subitization constraint) that limits the quantities appreciable without counting to three or four. This in turn implies that the numerical lexicon likely reached numbers that corresponded not only to bundling values (i.e., up to 10) but to the values of compound tokens as well (tens and hundreds), rather than being restricted to subitizable amounts.

\footnotetext{
${ }^{3}$ The idea that fingers (and possibly toes) were an early material form for Mesopotamian counting is inferred from extant number systems, where the strong somatic basis for numbers manifests as patterning by fives, tens, and twenties. This somatic basis is a function of the neurological interaction between the intraparietal sulcus (the part of the brain implicated in appreciating quantity; e.g., Ardila, 2010) and the angular gyrus (the part that "knows" the fingers and supports both finger-counting and calculating; e.g., Roux, Boetto, Sacko, Chollet, \& Trémoulet, 2003). Fingercounting spans the gamut of numerical elaboration (i.e., from emerging to highly elaborated systems), while the use of body parts other than the fingers (e.g., toes; other anatomical features) is associated with emerging number systems (especially ones that have not incorporated other material forms). Mesopotamian numbers would have shared these cross-cultural tendencies, as Ancient Near Eastern people are reasonably and plausibly construed to have had fivefingered hands and typical neurological functionality (and indeed, the latter is supported by linguistic evidence). A more detailed discussion is outside the present scope but is planned.
} 


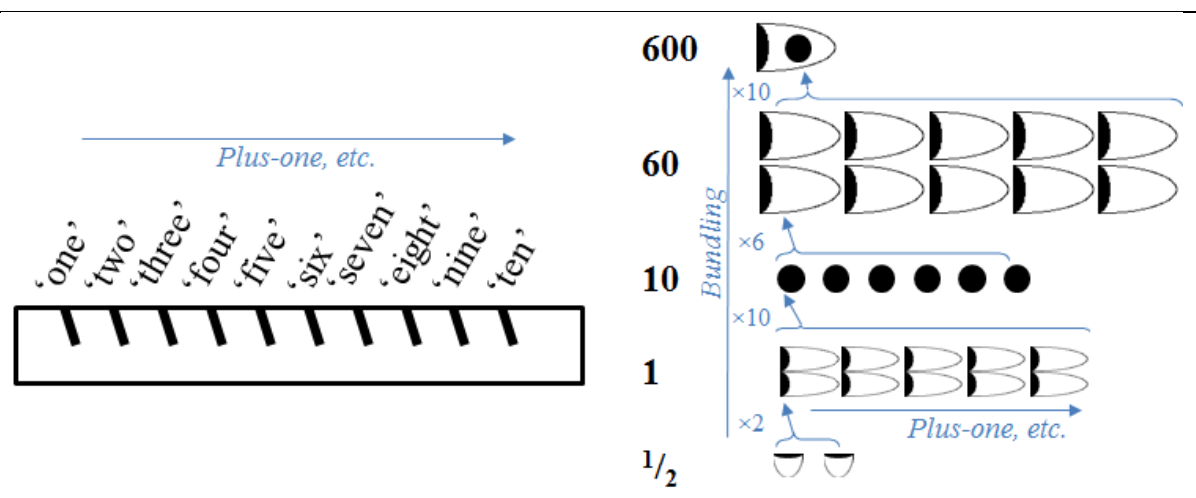

Fig. 4: Numerical representational of tallies (left) and tokens (right). In a tally, numerical representation is one-dimensional; total value is achieved by accumulating value along the single dimension. With tokens, there are more relations between numbers: those of sequential plus-one accumulation (the horizontal axis) and those implicit in bundling (the vertical axis); total value is achieved by accumulating value along both dimensions. The two-dimensional structure of tokens implies one-dimensional precursors like tallies and/or fingers.

\section{Material and Conceptual Change in Ancient Near Eastern Numbers}

If the possible evidence of fingers and tallies is accepted, the sequence of counting technologies in the Ancient Near East includes fingers, tallies, tokens, and the various numerical notations. In the analysis presented in Table 2, fingers and notations were treated as if they were material in the same way that physical devices like tallies and tokens are. Typically, fingers are thought of as biological supports to psychological capabilities like working memory, notations as signs and symbols. The assumption entailed that the conceptual boundaries between the body and the material (for fingers), and the material and the psychological (for numerical notations), needed to tolerate a degree of ambiguity in what they delimited. To bridge the ambiguity, Gibson's (1977, 1979) notion of affordance was used. An affordance is a relation between what an agent is capable of and what its environment enables it to do; here it designates the exploitable properties of a material form used for counting. Analysis of the affordances provided by the different counting technologies then allowed characterization of how they were similar (e.g., fingers and tallies, in influencing structural characteristics like linearity) and how they differed (fingers only, in being part of the body, etc.).

The analysis yielded the insight that new material forms were incorporated because they shared some affordances with older forms and because they brought new affordances that addressed limitations in older forms. New forms also brought new limitations into the system for numbers that eventually motivated the inclusion of new forms, and the contrast between newer and older forms provided elaborational opportunities. Newer forms were often associated with behavioral differences, and in some cases changes in psychological processing (e.g., the shift to knowledge-based calculation would have been associated with recruitment of the parts of the brain involved in recalling arithmetical facts, etc.), that would have affected how numbers were conceptualized. Concurrently, older forms appear to have persisted, both directly as a retained technology for representing and manipulating numbers and indirectly in the way their structure persisted in the way newer forms were used. These insights expand Gallagher's notion of an "affordance space," the "range of possibilities provided by any active movement in body or change in environment" delimited not just by the physiology and psychological capacities furnished 
evolutionarily, the stage of ontogenetic development applying to participating individuals, and the sociocultural practices informing behavioral possibilities (Gallagher, 2015), but by the capabilities, limitations, and structuring of the materials used and the concepts themselves as well.

Table 2: Analysis of Affordance Similarities and Differences

\begin{tabular}{|c|c|c|c|c|c|c|c|}
\hline & & Fingers & Tallies & Tokens & Impressions & Proto-cuneiform & Cuneiform \\
\hline \multirow{3}{*}{$\begin{array}{l}\text { Sequence of } \\
\text { technologies } \\
\text { used for } \\
\text { counting and } \\
\text { calculating }\end{array}$} & Appearance & "First" & $\begin{array}{l}\text { Late Upper } \\
\text { Paleolithic } \\
\text { (30,000-12,000BP) }\end{array}$ & $\begin{array}{l}\text { Neolithic } \\
\text { (8300-4500 BC) }\end{array}$ & $\begin{array}{l}\text { Chalcolithic } \\
(4500-3300 \mathrm{BC})\end{array}$ & $\begin{array}{l}\text { Early Bronze Age } \\
\text { (late } 4^{\text {th }} \text { mil. BC) }\end{array}$ & $\begin{array}{l}\text { Bronze Age } \\
\text { (3rd mil. BC) }\end{array}$ \\
\hline & Evidence & $\begin{array}{l}\text { Textual (from } 3^{\text {rd }} \\
\text { mil. BC) }\end{array}$ & Archaeological & Archaeological & Archaeological & Archaeological & Textual \\
\hline & Importance & Initial structure & $\begin{array}{l}\text { Transition to } \\
\text { material culture }\end{array}$ & $\begin{array}{l}\text { Knowledge- } \\
\text { based calculation }\end{array}$ & $\begin{array}{l}\text { Need for new } \\
\text { algorithms }\end{array}$ & $\begin{array}{l}\text { Need for new } \\
\text { algorithms }\end{array}$ & $\begin{array}{l}\text { Numbers as } \\
\text { entities or objects }\end{array}$ \\
\hline \multirow{3}{*}{$\begin{array}{l}\text { Embodied } \\
\text { characteristics }\end{array}$} & Neurological & Yes & No & No & No & No & No \\
\hline & Discriminability & Yes & Up to 3 or 4 & Unknown & Bundling & Bundling & Place value \\
\hline & Linear; order & Developed & Imposed & Imposed & Imposed & Imposed & Imposed \\
\hline \multirow{6}{*}{$\begin{array}{l}\text { Material } \\
\text { characteristics }\end{array}$} & Bundling & Anatomical & No & Metrological & Metrological & Metrological & Sexagesimal \\
\hline & Capacity & Five & Tens & Hundreds & Hundreds & Thousands & Thousands \\
\hline & Persistence & No & Yes & If contained & Yes & Yes & Yes \\
\hline & Manipulability & Limited & Fixed & High & Fixed & Fixed & Fixed \\
\hline & Integrity & Anatomical & Fixed & If contained & Fixed & Fixed & Fixed \\
\hline & Specified & In memory & In memory & Conjoined & Conjoined & Conjoined & Labeled \\
\hline \multirow{2}{*}{ Representation } & Dimensional & One & One & Two & Two & Two & Two \\
\hline & Concise & No & No & Increasing & No & Increasing & Yes \\
\hline \multirow{5}{*}{$\begin{array}{l}\text { Conceptual } \\
\text { change }\end{array}$} & Identity & Equivalence & Collection & Collection & Collection & Collection & Entity/object \\
\hline & Relations & Stable order & Plus-one, etc. & Metrological & Metrological & Metrological & Many (tables) \\
\hline & Operations & Accumulation & Accumulation & Grouping, etc. & Imposed & Imposed & Imposed \\
\hline & Algorithms & Simple & Simple & Complex & Imposed & Imposed & Imposed \\
\hline & Distributed & With language & Two forms & Three forms & Multiple forms & Multiple forms & Multiple forms \\
\hline
\end{tabular}

Note. Embodied characteristics are significantly influenced by psychological and physiological traits. Material characteristics are imposed (or enabled) by the material form. Representation: Characteristics applicable to how the material structure represents numerical information. Conceptual change: How the concept of number would have changed in conjunction with material, behavioral, and psychological change.

Four key transitions in the material sequence are highlighted below: Fingers influenced basic structure; tallies represented the transition to incorporating material culture; tokens represented the emergence of knowledge-based numeration; and written notations enabled numbers to become conceptualized as entities. These are also interactions with material forms that potentialize neural reorganizations (i.e., the neuronal recycling hypothesis of Dehaene \& Cohen, 2007): For example, knowledge-based numeration implies recruitment of the angular gyrus, which demonstrates activity during the recall of arithmetic facts (Grabner et al., 2009); while parietal activity predominates during the performance of mathematical tasks (Amalric \& Dehaene, 2016), the frontal lobes also show activity and imply the involvement of executive functions like intentionality and working memory.

- Fingers influence numbers toward linearity and stable order (Gelman \& Gallistel, 1978), structure that is "essential to most of [numbers'] mathematical properties" (Russell, 1920, p. 29) and which persists across subsequent material forms. As mentioned, the concept of number starts with the recognition that two sets of objects share the same cardinality. 
Representation of the concept by one of the sets in the comparison, typically the fingers, sets up an initial structuring - by fives and tens; in linear and stable order-as a function of what the hand is as an instantiating material form in interaction with other psychological, physiological, and behavioral capacities: As material device, the hand provides five digits, logical start and stop points in the outer fingers, and accumulation as counting proceeds across the hand. Working memory is limited in the number of items that can be held in active attention and manipulated mentally, necessitating the inclusion of material representations. Finger-counting, like any repetitive motor movement, becomes patterned in ways that maximize its efficiency and automaticity, which in turn reduces demands on attention and working memory and improves the reproducibility, reliability, and accessibility of the numerical information instantiated by the fingers. Language influences counting toward sequentiality through the seriality of the sound stream. While there may indeed be a sort of logical predestination to numerical ordering, numbers may be influenced toward linearity and stable order as much through the use of the hand as a material device as by the functional effectiveness in counting that magnitude ordering provides.

- Given sufficient societal motivation for counting beyond what the hand can provide (e.g., the need for amounts beyond those reasonably accumulated on the fingers; time durations longer than what the hand can feasibly represent), tallies are the kind of device typically incorporated into a number system once the limitations of the hand are encountered (similar material devices include knotted strings, torn leaves, collected pebbles, etc.). Tallies would have marked a key transition, from using the body as a device for counting, to involving material forms not part of the body. Material artifacts are sharable in ways that bodies and behaviors (especially those associated with social status and prestige) are typically not, making the number knowledge instantiated by devices more public and socially permitted, and less private and proscribed, than the number knowledge instantiated by the body. Relative to bodies and behaviors, material artifacts also have a higher plasticity and capacity for being modified to collect and consolidate social knowledge. This is a critical aspect of transmitting information to new individuals and between generations, not only because it makes the information available but because it can reduce acquisition to a matter of learning to use the device, eliminating the need for reinvention and often bypassing the need to master theories and principles.

- Tokens provided access to a more extensive and explicit set of numerical relations, operations, and algorithms for calculating, which are important as they provide the basis for knowledge-based calculating. Where tallies provided a few relations (e.g., plus one, more than, less than, not equal, etc.) and operations (accumulation), tokens provided the relations implicit in bundling values, and operations of accumulation, reduction, grouping, separation, and simplification (respectively, addition, subtraction, multiplication, reciprocals, and bundling-debundling). Tokens also enabled algorithms like the agrimensors' method of approximating the area of a field, attested as early as 3250 BC in the form of two exercises on a tablet from Uruk, W 19408,76 (Englund, 1998c; Nissen, Damerow, \& Englund, 1993; also see Fig. 5). Tokens' relations of value to each other necessitated that value-relations be learned and associated particular token shapes and sizes with specific values quantified in numerical terms. Tokens nonetheless represented quantity conceived in terms of collections, as tallies had, because they were meaningful only in aggregate, rather than individually. 


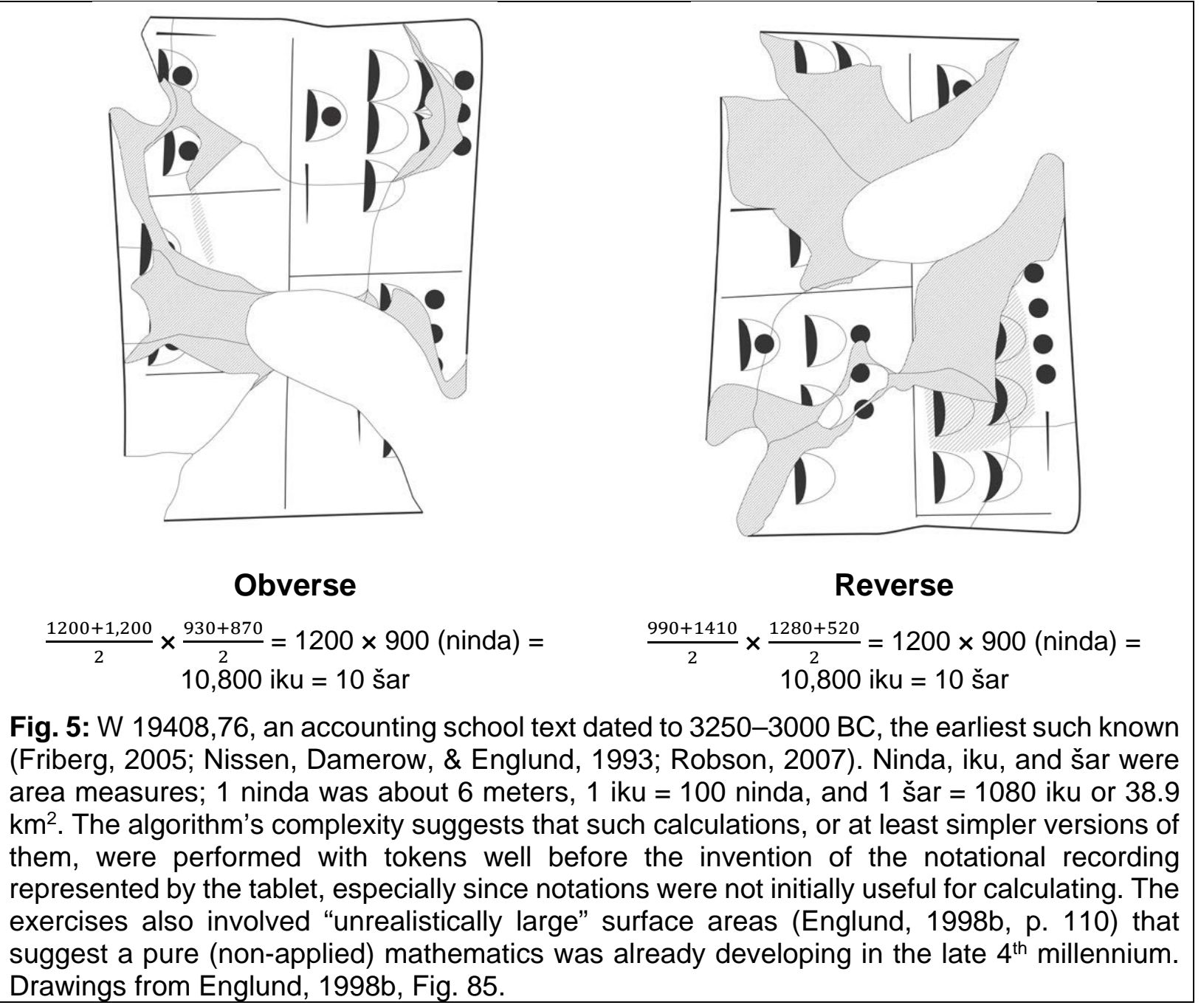

- Cuneiform notations enabled numbers to be conceptualized as entities through three critical attributes: They were handwritten, concise, and fixed. Writing by hand trained the brains of scribes to recognize individual notations as objects; this is a neural reorganization that occurs in literacy, as the part of the temporal lobe that recognizes objects, the fusiform gyrus, becomes trained to recognize written marks as if they were objects and to associate them lexically by interaction developed between the fusiform gyrus and the language centers of the brain (reviewed in Overmann, 2016b). Second, their concision allowed notations to be individuated, rather than remain collections as tokens were. Concision also enabled large volumes of detailed numerical relations to be recorded in the form of tables (e.g., multiplication tables; tables of reciprocals), which scribes reproduced and learned during training. This in turn yielded more options in calculating, as scribes could consult the tables or recall numerical relations from memory, in addition to performing the calculations with tokens. Concision in recording intermediate and final results would have also supported the development of greater complexity in calculation methods. Most importantly, numerical relations gave individual numbers an identity that would have reinforced their reconceptualization as objects or entities fostered by the neural training 
effects of handwriting. Third, the notations were fixed, as the impressions and archaic numerals had been, motivating the development of new algorithms that leveraged numerical knowledge to an even greater extent than token-based accounting did, algorithms that drew upon and thus reinforced the knowledge of numerical relations and the conceptualization of numbers in terms of relational identities.

Notations provide another reason for reconsidering the abstract-concrete distinction: Usually considered to fall on the "abstract" side, notations remained closely bound to their material realizers, exhibiting a concreteness that is usually obscured by their abstract designation. Yes, they could be written without commodity labels and were manipulated in complex algorithms, functioning as conceptual entities related numerically to similar entities. But commodity labels were understood contextually when omitted, and in calculations notations remained closely tied to practical domains (hence, Høyrup's [1994] designation of the Babylonian mathematics tradition as subscientific). More interestingly, the numbers represented notationally differed in arithmetical operations in ways that evoke the material forms used for calculation: Babylonian mathematics had, for example, two additions and two subtractions, which differed according to whether the original quantities remained recognizable or not (e.g., in addition performed with commingled tokens, the original quantities would be lost once they joined the pile) (Høyrup, 2002a). This contrasts with modern numbers, which achieve the same sums and differences regardless of whether calculations are performed with fingers, abaci, or computers. Which is only to say that Babylonian and modern numbers are different concepts represented by different material forms.

What the cuneiform notations ultimately yielded, however, was a semiotic system in which the elements (numbers) were meaningful entities whose identity derived from their identification as objects and the interrelations providing calculational access and complexity. This system informed the later mathematics of the Greeks, who further elaborated the system by considering the patterns made by numerical relations and operations (e.g., odd/even; multiplication sets) (Klein, 1968), work built upon the foundation initially established by the Mesopotamians with tokens and tallies. While the Greek elaboration also perhaps shows more clearly a role for ontological and epistemological imagination - why does someone ask what a number is, or whether $1+1$ will always and under every circumstance yield 2-it also shows that such imagination acts within and at the boundaries of an existing system, elaborating its substance, testing its limits, and taking for granted the ideas and social knowledge received from the work of many earlier hands in the form of materially instantiated knowledge. In such systems in general, there may be a role for Piaget's ontogenetic effects in providing a familiar mastery that is well positioned to question the system's parameters, but there is also a significant role for the material component, particularly in numbers, who so happily match material structures' seemingly limitless potential to instantiate and illuminate novel numerical relations, and the human psychological, behavioral, and physiological abilities that discover and exploit them. 


\section{Acknowledgements}

J. Cale Johnson, Dwight Read, Rex Welshon, Robert Englund, Steven Chrisomalis, and an anonymous reviewer offered many helpful comments on the initial draft; any remaining errors and omissions are, of course, my own.

\section{References}

Amalric, M., \& Dehaene, S. (2016). Origins of the brain networks for advanced mathematics in expert mathematicians. Proceedings of the National Academy of Sciences of the United States of America, 113(18), 4909-4917.

Ardila, A. (2010). On the evolution of calculation abilities. Frontiers in Evolutionary Neuroscience, 2, 1-7.

Blažek, V. (1999). Numerals: Comparative etymological analyses and their implications: Saharan, Nubian, Egyptian, Berber, Kartvelian, Uralic, Altaic and Indo-European languages. Brno: Masarykova Univerzita.

Branner, D. P. (2006). China: Writing system. In K. Brown (Ed.), The encyclopedia of language and linguistics ( $2^{\text {nd }}$ ed., pp. 331-341). Amsterdam: Elsevier.

Brouwer, L. E. J. (1981). Brouwer's Cambridge lectures on intuitionism. Cambridge: Cambridge University Press.

Chrisomalis, S. (2005). Evaluating ancient numeracy: Social versus developmental perspectives on ancient Mesopotamian numeration (pp. 1-21). Paper delivered to the annual meeting of the Jean Piaget Society (Vancouver, British Columbia).

Chrisomalis, S. (2010). Numerical notation: A comparative history. Cambridge: Cambridge University Press.

Comrie, B. (1989). Language universals and linguistic typology ( $2^{\text {nd }}$ ed.). Chicago: University of Chicago Press.

Comrie, B. (2013). Numeral bases. In M. S. Dryer \& M. Haspelmath (Eds), World atlas of language structures online. Leipzig: Max Planck Institute for Evolutionary Anthropology. http://wals.info/chapter/131

Conant, L. L. (1896). The number concept: Its origin and development. New York: Macmillan and Co.

Corbett, G. G. (2000). Number. Cambridge: Cambridge University Press.

Crossley, J. N. (1987). The emergence of number. Singapore: World Scientific.

Cuneiform Digital Library. (2015). Oriental Institute, University of Oxford. http://cdli.ox.ac.uk

Dahl, J. L. (2015). Comment on "Numerosity structures the expression of quantity in lexical numbers and grammatical number.” Current Anthropology, 56(5), 647-648.

Damerow, P. (1988). Individual development and cultural evolution of arithmetical thinking. In S. Strauss (Ed.), Ontogeny, phylogeny, and historical development: The Tel Aviv annual workshop in human development (pp. 125-152). Norwood: Ablex.

Damerow, P. (1996a). Number as a second-order concept. Science in Context, 9(2), 139-149.

Damerow, P. (1996b). Prehistory and cognitive development. In M. Killen (Ed.), Invited lecture at the twenty-fifth annual symposium of the Jean Piaget Society, Berkeley, June 1 - June 3, 1995 (pp. 137). Berlin: Max Planck Institute for the History of Science.

Damerow, P. (2007). The material culture of calculation: A theoretical framework for a historical epistemology for the concept of number. In U. Gellert \& E. Jablonka (Eds), Mathematisation and demathematisation: Social, philosophical and educational ramifications (pp. 19-56). Rotterdam: Sense Publishers.

Damerow, P. (2010). Abstraction and representation: Essays on the cultural evolution of thinking. Dordrecht: Kluwer Academic. 
Damerow, P. (2012). The origins of writing and arithmetic. In J. Renn (Ed.), The globalization of knowledge in history (pp. 153-173). Berlin: Max Planck Research Library for the History and Development of Knowledge.

Damerow, P., \& Meinzer, H.-P. (1995). Computertomografische Untersuchung ungeöffneter archaischer Tonkugeln aus Uruk, W 20987, 9, W 20987, 11 und W 20987, 12. Baghdader Mitteilungen, 26, 7-33.

Dasen, P. R. (1994). Culture and cognitive development from a Piagetian perspective. In W. J. Lonner \& R. S. Malpass (Eds), Psychology and culture (pp. 145-149). Boston: Allyn and Bacon.

Dehaene, S., \& Cohen, L. (2007). Cultural recycling of cortical maps. Neuron, 56(2), 384-398.

Di Paolo, E. A., Rohde, M., \& de Jaegher, H. (2010). Horizons for the enactive mind: Values, social interaction, and play. In J. Stewart, O. Gapenne, \& E. A. di Paolo (Eds), Enaction: Toward a new paradigm for cognitive science (pp. 33-87). Cambridge: MIT Press.

Dreyfus, T. (1991). Advanced mathematical thinking processes. In D. O. Tall (Ed.), Advanced mathematical thinking (pp. 25-41). New York: Kluwer.

Edzard, D. O. (1980). Sumerisch 1 bis 10 in Ebla. Studi Eblaiti, III(5-8), 121-127.

Englund, R. K. (1998a). Review: Denise Schmandt-Besserat, How writing came about. Written Language and Literacy, 1, 257-261.

Englund, R. K. (1998b). Proto-Elamite. In Encyclopeedia Iranica (Vol. VIII/3, pp. 325-330). Cosa Mesa: Mazda.

Englund, R. K. (1998c). Texts from the Late Uruk period. In Mesopotamien: Späturuk-Zeit und Frühdynastische Zeit (pp. 15-233). Freiburg: Universitätsverlag.

Englund, R. K. (2004). The state of decipherment of Proto-Elamite. In S. D. Houston (Ed.), The first writing: Script invention as history and process (pp. 100-149). Cambridge: Cambridge University Press.

Epps, P., Bowerin, C., Hansen, C. A., Hill, J. H., \& Zentz, J. (2012). On numeral complexity in huntergatherer languages. Linguistic Typology, 16(1), 41-109.

Fauconnier, G. (1997). Mappings in thought and language. Cambridge: Cambridge University Press.

Ferrari, P. L. (2003). Abstraction in mathematics. Philosophical Transactions of the Royal Society of London. Series B, Biological Sciences, 358(1435), 1225-1230.

Frege, G. (1953). The foundations of arithmetic: A logical-mathematical investigation into the concept of number $\left(2^{\text {nd }}\right.$ rev. ed.). J. L. Austin, trans. New York: Harper \& Brothers.

Friberg, J. (1994). Preliterate counting and accounting in the Middle East: A constructively critical review of Schmandt-Besserat's Before writing. Orientalistische Literaturzeitung, 89(5-6), 477-489.

Friberg, J. (2005). Unexpected links between Egyptian and Babylonian mathematics. Singapore: World Scientific.

Friberg, J. (2007). A remarkable collection of Babylonian mathematical texts. New York: Springer Science+Business Media, LLC.

Gallagher, S. (2015). Doing the math: Calculating the role of evolution and enculturation in the origins of geometrical and mathematical reasoning. Progress in Biophysics and Molecular Biology, 119, 341-346.

Gelman, R., \& Gallistel, C. R. (1978). The child's understanding of number. Cambridge: The President and Fellows of Harvard College.

Gibson, J. J. (1977). The theory of affordances. In R. Shaw \& J. Bransford (Eds), Perceiving, acting, and knowing: Toward an ecological psychology (pp. 127-143). Hillsdale: Lawrence Erlbaum.

Gibson, J. J. (1979). The ecological approach to visual perception. Boston: Houghton Mifflin.

Glassner, J.-J. (2000). The invention of cuneiform: Writing in Sumer. Z. Bahrani \& M. van de Mieroop, trans. Baltimore: Johns Hopkins University Press.

Gowers, T. (2002). Mathematics: A very short introduction. Oxford: Oxford University Press.

Gowers, T. (Ed.). (2008). The Princeton companion to mathematics. Princeton: Princeton University Press. 
Grabner, R. H., Ansari, D., Koschutnig, K., Reishofer, G., Ebner, F., \& Neuper, C. (2009). To retrieve or to calculate? Left angular gyrus mediates the retrieval of arithmetic facts during problem solving. Neuropsychologia, 47(2), 604-608.

Greenberg, J. H. (1978). Generalizations about numeral systems. In Universals of human language (pp. 249-295). Stanford: Stanford University Press.

Haas, C. (1996). Writing technology: Studies on the materiality of literacy. New York: Routledge.

Heine, B. (2003). Grammaticalization. In B. D. Joseph \& R. D. Janda (Eds), The handbook of historical linguistics (pp. 575-601). Malden: Blackwell.

Henkelman, W. F. M., \& Folmer, M. L. (2016). Your tally is full! On wooden credit records in and after the Achaemenid empire. In K. Kleber \& R. Pirngruber (Eds), Silver, money, and credit: A tribute to Robartus J. van Der Spek on the occasion of his 65th birthday (pp. 133-239). Leiden: Nederlands Instituut voor het Nabije Oosten.

Henrich, J., Heine, S. J., \& Norenzayan, A. (2010). The weirdest people in the world? Behavioral and Brain Sciences, 33(2-3), 61-135.

Høyrup, J. (1994). In measure, number, and weight: Studies in mathematics and culture. S. Restivo, ed. SUNY Series in Science, Technology, and Society. Albany: State University of New York Press.

Høyrup, J. (2002a). Lengths, widths, surfaces: A portrait of Old Babylonian algebra and its kin. New York: Springer.

Høyrup, J. (2002b). A note on Old Babylonian computational techniques. Historia Mathematica, 29(2), 193-198.

Høyrup, J. (2016). Embedding: Multipurpose device for understanding mathematics and its development, or empty generalization? Gaṇita Bhāratī, 38(1), 1-29.

Hutchins, E. (1995). Cognition in the wild. Cambridge: MIT Press.

Hutchins, E. (2005). Material anchors for conceptual blends. Journal of Pragmatics, 37(10), 1555-1577.

Ifrah, G. (2000). The universal history of numbers: From prehistory to the invention of the computer. D. Bellos, E. F. Harding, I. Monk, \& S. Wood, trans. New York: John Wiley \& Sons.

Inhelder, B., \& Piaget, J. (1958). The growth of logical thinking: From childhood to adolescence (new impression). A. Parsons \& S. Milgram, trans. London: Routledge \& Kegan Paul PLC.

Jasim, S. A., \& Oates, J. (1986). Early tokens and tablets in Mesopotamia: New information from Tell Abada and Tell Brak. World Archaeology, 17(3), 348-362.

Klein, J. (1968). Greek mathematical thought and the origin of algebra. E. Brann, trans. New York: Dover.

Kline, M. (1967). Mathematics for the nonmathematician. New York: Dover Publications.

Lazaridis, I., Nadel, D., Rollefson, G., Merrett, D. C., Rohland, N., Mallick, S., ... Reich, D. (2016). Genomic insights into the origin of farming in the Ancient Near East. Nature, 536(7617), 419-424.

Lévy-Bruhl, L. (1910). Les fonctions mentales dans les sociétés inférieures. Paris: Librairie Félix Alcan.

Lévy-Bruhl, L. (1927). L’âme primative. Paris: Librairie Félix Alcan.

Linnebo, Ø. (2013). Platonism in the philosophy of mathematics. In E. N Zalta (Ed.), Stanford encyclopedia of philosophy. http: //plato.stanford.edu/archives/win2013/ entries/platonism-mathematics/

Locke, J. (1690). An essay concerning human understanding (1854 print). Philadelphia: Hayes \& Zell.

MacGinnis, J., Monroe, M. W., Wicke, D., \& Matney, T. (2014). Artefacts of cognition: The use of clay tokens in a Neo-Assyrian provincial administration. Cambridge Archaeological Journal, 24(2), 289-306.

Malafouris, L. (2010). Grasping the concept of number: How did the sapient mind move beyond approximation? In C. Renfrew \& I. Morley (Eds), The archaeology of measurement: Comprehending heaven, earth and time in ancient societies (pp. 35-42). Cambridge: Cambridge University Press.

Malafouris, L. (2013). How things shape the mind: A theory of material engagement. Cambridge: MIT Press. 
Martzloff, J.-C. (1997). A history of Chinese mathematics. S. S. Wilson, trans. Berlin: Springer-Verlag.

Mattessich, R. (1994). Archaeology of accounting and Schmandt-Besserat's contribution. Accounting, Business \& Financial History, 4(1), 5-28.

Miller, H. (1980). Money and how it gets that way. Challenge: The Magazine of Economic Affairs, 23(1), 3-5.

Morgan, J. (1852). The life and adventures of William Buckley: Thirty-two years a wanderer amongst the aborigines of the then unexplored country around Port Phillip, now the province of Victoria $\left(19^{\text {th }}\right.$ ed.). Adelaide: Griffin Press.

Neugebauer, O. E. (1957). The exact sciences in antiquity ( $2^{\text {nd }}$ ed.). New York: Dover.

Nicolopoulou, A. (1997). The invention of writing and the development of numerical concepts in Sumeria: Some implications for developmental psychology. In M. Cole, Y. Engeström, \& O. Vasquez (Eds), Mind, culture, and activity (pp. 205-240). Cambridge: Cambridge University Press.

Nissen, H. J. (1986). The archaic texts from Uruk. World Archaeology, 17(3), 317-334.

Nissen, H. J., Damerow, P, \& Englund, R. K. (1993). Archaic bookkeeping: Early writing and techniques of economic administration in the Ancient Near East. P. Larsen, trans. Chicago: University of Chicago Press.

Oesterdiekhoff, G. W. (2016). Is a forgotten subject central to the future development of sciences? Jean Piaget on the interrelationship between ontogeny and history. Personality and Individual Differences, 98, 118-126.

Overmann, K. A. (2015). Numerosity structures the expression of quantity in lexical numbers and grammatical number. Current Anthropology, 56(5), 638-653.

Overmann, K. A. (2016a). Materiality in numerical cognition: Material Engagement Theory and the counting technologies of the Ancient Near East. Doctoral thesis, University of Oxford.

Overmann, K. A. (2016b). Beyond writing: The development of literacy in the Ancient Near East. Cambridge Archaeological Journal, 26(2), 285-303.

Overmann, K. A. (2017). Concepts and how they get that way. Phenomenology and the Cognitive Sciences, 1-16. https://doi.org/10.1007/s11097-017-9545-8

Peano, G. (1889). Arithmetices principia: Nova methodo exposita. Rome: Fratres Bocca.

Peirce, C. S. (1906). Prolegomena to an apology for pragmaticism. The Monist, 16(4), 492-546.

Pelleschi, G. (1896). The Mataco Indians and their language. In Boletin del Instituto Geográfico Argentino, Vols. 17-18. Buenos Aires: Imp. "La Buenos Aries."

Piaget, J. (1928). Logique génétique et sociologie. Revue Philosophique de la France et de l'Étranger, 105, 167-205.

Piaget, J. (1937). The construction of reality in the child. M. Cook, trans. New York: Basic.

Piaget, J. (1952). The child's conception of number. Jean Piaget: Selected works, Vol. II. C. Gattegno \& F. M. Hodgson, trans. Abingdon: Routledge.

Plato. (1892). Philebus. In The dialogues of Plato: Parmenides, Theaetetus, Sophist, Statesman, Philebus ( $3^{\text {rd }}$ ed.). B. Jowett, trans. Oxford: Oxford University Press.

Powell, M. A. Jr. (1971). Sumerian Numeration and Metrology. Doctoral dissertation, University of Minnesota.

Reese, D. S. (2002). On the incised cattle scapulae from the East Mediterranean and Near East. Bonner Zoologische Beitrage, 50, 183-198.

Robson, E. (2007). Mesopotamian mathematics. In V. Katz (Ed.), The mathematics of Egypt, Mesopotamia, China, India, and Islam: A sourcebook (pp. 57-186). Princeton: Princeton University Press.

Robson, E. (2008). Mathematics in ancient Iraq: A social history. Princeton: Princeton University Press. 
Rosen, G. (2014). Abstract objects. In E. N. Zalta (Ed.), Stanford encyclopedia of philosophy. http: //plato.stanford.edu/archives/fall2014/entries/abstract-objects/

Rotman, B. (1987). Signifying nothing: The semiotics of zero. Stanford: Stanford University Press.

Rotman, B. (2000). Mathematics as sign: Writing, imagining, counting. Stanford: Stanford University Press.

Roux, F.-E., Boetto, S., Sacko, O., Chollet, F., \& Trémoulet, M. (2003). Writing, calculating, and finger recognition in the region of the angular gyrus: A cortical stimulation study of Gerstmann Syndrome. Journal of Neurosurgery, 99(4), 716-727.

Russell, B. (1920). Introduction to mathematical philosophy ( $2^{\text {nd }}$ ed.). London: George Allen \& Unwin.

Saxe, G. B. (2012). Cultural development of mathematical ideas. Cambridge: Cambridge University Press.

Schmandt-Besserat, D. (1977). An archaic recording system and the origin of writing. Malibu: Undena.

Schmandt-Besserat, D. (1978). The earliest precursor of writing. Scientific American, 238(6), 50-59.

Schmandt-Besserat, D. (1981). From tokens to tablets: A re-evaluation of the so-called "numerical tablets. Visible Language, 15(4), 321-344.

Schmandt-Besserat, D. (1982). The emergence of recording. American Anthropologist, New Series, 84(4), 871-878.

Schmandt-Besserat, D. (1986). The origins of writing: An archaeologist's perspective. Written Communication, 3(1), 31-45.

Schmandt-Besserat, D. (1992a). Before writing: From counting to cuneiform (2 vols). Austin: University of Texas Press.

Schmandt-Besserat, D. (1992b). How writing came about. Austin: University of Texas Press.

Schmandt-Besserat, D. (2010). The token system of the Ancient Near East: Its role in counting, writing, the economy and cognition. In C. Renfrew \& I. Morley (Eds), The archaeology of measurement: Comprehending heaven, earth and time in ancient societies (pp. 27-34). Cambridge: Cambridge University Press.

Schmandt-Besserat, D. (2016). The earliest precursor of writing. In D. Crowley \& P. Heyer (Eds), Communication in history: Technology, culture, society ( $6^{\text {th }}$ ed., pp. 1-16). New York: Routledge.

Sfard, A., \& Linchevski, L. (1994). The gains and the pitfalls of reification? The case of algebra. Educational Studies in Mathematics, 26(2-3), 191-228.

Thureau-Dangin, F. (1921). Numération et métrologie sumériennes. Revue d'Assyriologie et d'archéologie orientale, 18(3), 123-142.

Tompack, R. S. (1978). A comparative Semitic lexicon of the Phoenician and Punic languages. Missoula: Scholar's Press.

Traugott, E. C. \& Heine, B. (1991). Introduction. In E. C. Traugott \& B. Heine (Eds), Approaches to grammaticalization, Volume II: Focus on types of grammatical markers (pp. 1-14). Amsterdam: John Benjamins.

Vaiman, A. A. (1961). Sumero-Babylonian mathematics in the third to first millennia BC. Moscow: Izdatel'stvo Vostocnoj Literatury.

Vogel, K. (1959). Vorgriechische Mathematik. II. Die Mathematik der Babylonier. Mathematische Studienhefte, 2. Hannover: Hermann Schroedel.

Whitehead, A. N., \& Russell, B. (1927). Principia mathematica (Vol. II, $2^{\text {nd }}$ ed.). Cambridge: Cambridge University Press.

Zhang, J., \& Norman, D. A. (1995). A representational analysis of numeration systems. Cognition, 57, 271-295.

Zimansky, P. (1993). Review of Denise Schmandt-Besserat's Before writing, volumes I and II. Journal of Field Archaeology, 20(4), 513-517. 